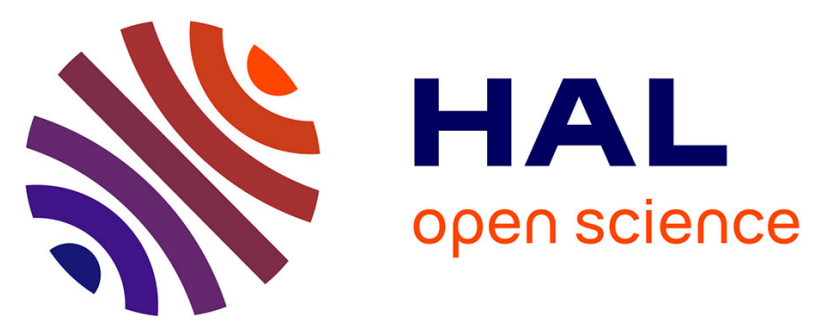

\title{
Efficient Peroxydisulfate Activation Process Not Relying on Sulfate Radical Generation for Water Pollutant Degradation
}

Tao Zhang, Yin Chen, Yuru Wang, Julien Le Roux, Yang Yang, Jean-Philippe Croue

\section{To cite this version:}

Tao Zhang, Yin Chen, Yuru Wang, Julien Le Roux, Yang Yang, et al.. Efficient Peroxydisulfate Activation Process Not Relying on Sulfate Radical Generation for Water Pollutant Degradation. Environmental Science and Technology, 2014, 48 (10), 10.1021/es501218f . hal-01211451

\section{HAL Id: hal-01211451 \\ https://hal-enpc.archives-ouvertes.fr/hal-01211451}

Submitted on 31 Oct 2016

HAL is a multi-disciplinary open access archive for the deposit and dissemination of scientific research documents, whether they are published or not. The documents may come from teaching and research institutions in France or abroad, or from public or private research centers.
L'archive ouverte pluridisciplinaire HAL, est destinée au dépôt et à la diffusion de documents scientifiques de niveau recherche, publiés ou non, émanant des établissements d'enseignement et de recherche français ou étrangers, des laboratoires publics ou privés.

$$
\text { Copyright }
$$




\section{Efficient peroxydisulfate activation process not relying on sulfate radical generation for water pollutant degradation}

Tao Zhang ${ }^{a}$, Yin Chen ${ }^{b}$, Yuru Wang $^{a}$, Julien Le Roux ${ }^{a}$, Yang Yang ${ }^{c}$ and Jean-Philippe Croué ${ }^{*}$

a. Water Desalination and Reuse Center, King Abdullah University of Science and Technology, Thuwal 4700, Kingdom of Saudi Arabia

b. KAUST Catalysis Center, King Abdullah University of Science and Technology, Thuwal 4700,

$$
\text { Kingdom of Saudi Arabia }
$$

c. Advanced Nanofabrication Imaging and Characterization Lab, King Abdullah University of Science and Technology, Thuwal 4700, Kingdom of Saudi Arabia

* Corresponding author: Tel.: + 966 (0) 28082984.

E-mail address: jp.croue@kaust.edu.sa 
TOC Art

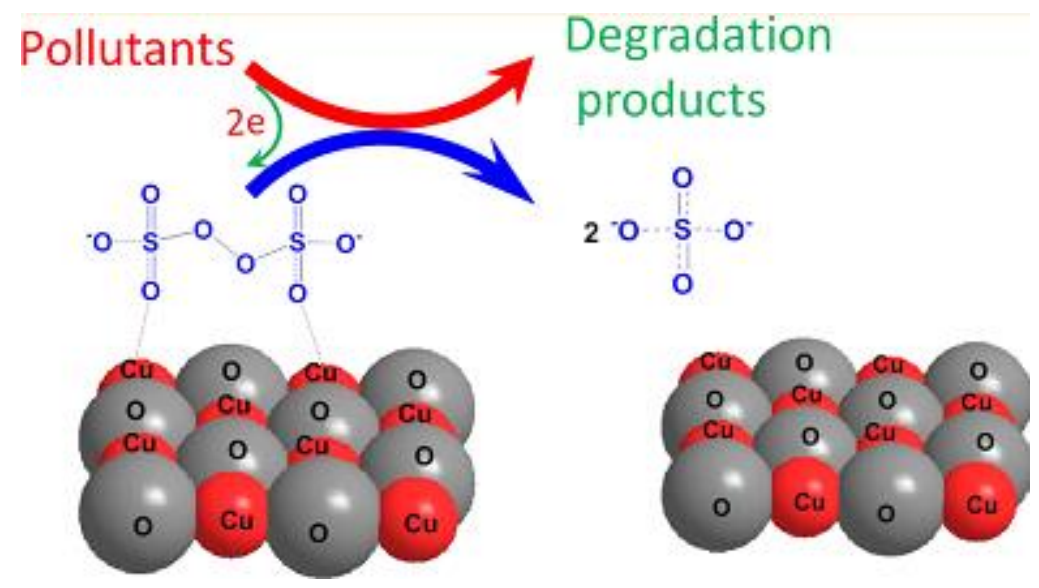




\section{ABSTRACT}

Peroxydisulfate (PDS) is an appealing oxidant for contaminated groundwater and toxic industrial wastewaters. Activation of PDS is necessary for application because of its low reactivity. Present activation processes always sulfate radicals as actual oxidants which unselectively oxidize organics and halide anions reducing oxidation capacity of PDS and producing toxic halogenated products. Here we report that copper oxide $(\mathrm{CuO})$ can efficiently activate PDS under mild conditions without producing sulfate radicals. The $\mathrm{PDS} / \mathrm{CuO}$ coupled process is most efficient at neutral $\mathrm{pH}$ for decomposing a model compound, 2,4-dichlorophenol (2,4-DCP). In a continuous-flow reaction with an empty-bed contact time of $0.55 \mathrm{~min}$, over 90\% 2,4-DCP (initially $20 \mu \mathrm{M}$ ) and $90 \%$ of adsorbable organic chlorine $(\mathrm{AOCl})$ can be removed at the PDS/2,4-DCP molar ratio of 1 and 4, respectively. Based on kinetic study and surface characterization, PDS is proposed to be first activated by $\mathrm{CuO}$ through outer-sphere interaction, the rate-limiting step, followed by a rapid reaction with $2,4-\mathrm{DCP}$ present in the solution. In the presence of ubiquitous chloride ions in groundwaters/industrial wastewater, the $\mathrm{PDS} / \mathrm{CuO}$ oxidation shows significant advantages over sulfate radical oxidation by achieving much higher 2,4-DCP degradation capacity and avoiding the formation of highly chlorinated degradation products. This work provides a new way of PDS activation for contaminant removal. 


\section{INTRODUCTION}

Persulfates, including peroxymonosulfate (PMS) and peroxydisulfate (PDS), have received increasing interest in recent years in both research and application for the remediation of organic pollutants in groundwater and wastewaters. They are relatively stable, thus favoring storage and transportation. When activated by alkaline, UV, heat and transition metals, they can produce strong sulfate radicals. ${ }^{1-5}$ PDS $(\$ 0.74$ per $\mathrm{kg})$ is much cheaper than PMS (sold as Oxone $\left(\mathrm{KHSO}_{5} \cdot 1 / 2 \mathrm{KHSO}_{4} \cdot 1 / 2 \mathrm{~K}_{2} \mathrm{SO}_{4}\right), \$ 2.2$ per kg) and even cheaper than $\mathrm{H}_{2} \mathrm{O}_{2}(\$ 1.5$ per $\mathrm{kg})$, thus having a better application potential. ${ }^{6-8}$ Activated PDS is applied for in situ chemical oxidation (ISCO) for contaminated groundwater. ${ }^{9}$ It could also be an alternative to Fenton or Fenton-like oxidation for the treatment of toxic wastewaters containing high concentrations of organic contaminants. ${ }^{10,11}$

Since PDS itself has very low reactivity towards organic pollutants, activation processes are necessary for its application. ${ }^{9,}{ }^{12}$ Heating and alkaline addition are usually recommended as feasible PDS activation methods for ISCO. ${ }^{3,13} \mathrm{UV}$ irradiation leading to homolytic cleavage of PDS is a well-known wet oxidation technique applied in TOC analyzers. Electron donors such as low valent metals $\left(\mathrm{Fe}^{\mathrm{o}}, \mathrm{Fe}^{2+}\right.$ and $\left.\mathrm{Ag}^{+}\right)$can also react with PDS to generate sulfate radicals. ${ }^{1,14,15}$ All these activation methods intensively consume energy or chemicals. It was recently reported that some organic compounds (e.g. quinones and phenoxides) could also react with PDS to generate sulfate radicals, ${ }^{16,17}$ but these organics cannot be artificially introduced into contaminated waters for technical and environmental reasons (i.e., toxicity). Metal oxides or minerals (e.g., $\mathrm{Fe}_{2} \mathrm{O}_{3}, \alpha-\mathrm{FeOOH}$ and $\mathrm{MnO}_{2}$ ) received particular attention to heterogeneously activate PDS, because they are not consumed during the activation and no additional energy is required. ${ }^{18,}{ }^{19}$ However, the low efficiency of present heterogeneous activation processes in terms of long contact time (usually in 
days) and high PDS dose requested (over 100 times higher than the pollutant concentration) is still a major limitation for its industrial application. Development of efficient and cost-effective new activation processes is necessary for PDS application.

Nearly all present PDS activation processes generate sulfate radical as the main oxidant species.

Sulfate radical $\left(E^{\mathrm{o}}=2.5-3.1 \mathrm{~V}\right)$ is very reactive toward organic contaminants and competing organic/inorganic constituents in water, ${ }^{9,20,21}$ exerting considerable negative side effects to the treatment of real water/wastewaters. For example, ubiquitous chloride ions in water/wastewater can be easily oxidized to chlorine radicals $\left(\mathrm{Cl}_{2}{ }^{--}\right)$, which not only reduces pollutant degradation rate but also leads to the formation of highly chlorinated products. ${ }^{22}$ Bromide in water can also be oxidized to bromate by sulfate radicals. ${ }^{23}$ Industrial application of such technology requires simultaneous minimization of hazardous product formation and maximization of PDS oxidation capacity. We anticipate that this objective could be approached through partial PDS activation without generating the unselective sulfate radicals. However, it is unknown yet whether PDS can be activated without generating sulfate radicals and how effective such activation can be.

In this work, $\mathrm{CuO}$ particles were tested in improving PDS oxidation of a model compound, 2,4-dichlorophenol (2,4-DCP), without generating sulfate radicals. The efficiency and durability of the PDS/CuO oxidation were evaluated with a continuous-flow reaction mode. The kinetics, mechanism, and selectivity of this oxidation process were further investigated. Its advantages over sulfate radical oxidation were also demonstrated in aspects of oxidation capacity and degradation products.

\section{EXPERIMENTAL SECTION}


Metal oxide preparation and characterization. Seven metal oxides (i.e., $\mathrm{Fe}_{2} \mathrm{O}_{3}$, $\mathrm{MnO}_{2}, \mathrm{CuO}, \mathrm{ZnO}, \mathrm{TiO}_{2}, \mathrm{MoO}_{3}$, and $\mathrm{CeO}_{2}$ ) were prepared with calcination of their derivatives $\left(\mathrm{Fe}\left(\mathrm{NO}_{3}\right)_{3} \cdot 9 \mathrm{H}_{2} \mathrm{O}(\geqslant 98 \%), \quad \mathrm{Mn}\left(\mathrm{NO}_{3}\right)_{2} \cdot \mathrm{xH}_{2} \mathrm{O}(98 \%), \quad \mathrm{Cu}-\left(\mathrm{NO}_{3}\right)_{2} \cdot 3 \mathrm{H}_{2} \mathrm{O}(98 \%), \quad \mathrm{Zn}\left(\mathrm{NO}_{3}\right)_{2} \cdot 6 \mathrm{H}_{2} \mathrm{O}\right.$ (98\%), $\mathrm{Ti}\left(\mathrm{OC}_{3} \mathrm{H}_{7}\right)_{4}(98 \%),\left(\mathrm{NH}_{4}\right)_{2} \mathrm{MoO}_{4}(>99 \%)$, and $\mathrm{Ce}\left(\mathrm{NO}_{3}\right)_{3} \cdot 6 \mathrm{H}_{2} \mathrm{O}$ (99\%)) (Sigma-Aldrich) under $450^{\circ} \mathrm{C}$ for two hours. BET surface area and average pore size of these oxides were determined on a Micromeritics ASAP 2420 analyzer. Average particle size was measured on a Mastersizer 2000 laser particle size analyzer. $\mathrm{pH}_{\mathrm{pzc}}(\mathrm{pH}$ at which the surface is zero-charged) was determined with acid-base titration. All the surface characterization results are listed in Table S1 of the Supporting Information (SI). The density of surface exposed $\mathrm{Cu}^{\mathrm{II}}$ on $\mathrm{CuO}$ prepared at $450{ }^{\circ} \mathrm{C}$ was determined with $\mathrm{O}_{2}$ adsorption on a Micromeritics ASAP 2020C. A density of $3.3 \mu \mathrm{mol} \mathrm{g}^{-1}$ was determined, approximating $7 \mathrm{Cu}^{\mathrm{II}}$ sites per $\mathrm{nm}^{2}$. Its crystalline was characterized with $\mathrm{XRD}$ (Bruker D8 A25).

Experimental procedure. Batch reaction. Experiments were conducted in a brown glass bottle. Predetermined volumes of model compound and PDS $\left(\mathrm{K}_{2} \mathrm{~S}_{2} \mathrm{O}_{8}\right.$ from SigmaAldrich) stock solutions were injected into $100 \mathrm{~mL}$ Milli-Q water to get the desired initial concentrations. Tetraborate $(10 \mathrm{mM})$ rather than phosphate was used as a buffer for most of the reactions, because phosphate is a strong coordinate for transition metals. The mixture was magnetically stirred at a rotary speed of $600 \mathrm{rpm}$ and room temperature $\left(20^{\circ} \mathrm{C}\right)$. Specified doses of oxide particles were introduced into the prepared solution to start the reaction. Samples withdrawn at different time intervals were filtered through $0.45 \mu \mathrm{m}$ glass fiber filters. To analyze the concentration of model compounds, sodium nitrite was immediately introduced into the filtrate to quench residual PDS. To analyze PDS residuals, EDTA stock solution $(4 \mathrm{mM})$ prepared in a phosphate buffer $(\mathrm{pH}=7.0,500$ 
$\mathrm{mM}$ ) was introduced into the filtrate with a volume percentage of $2 \%$ to scavenge any PDS decomposition initiated by metal ions.

Continuous flow reaction. An empty Waters HPLC column $(4.6 \times 75 \mathrm{~mm})$ was filled up with 3.0 $\mathrm{g}$ of $\mathrm{CuO}$ particles $\left(450{ }^{\circ} \mathrm{C}\right.$ calcined). A prepump (LabAlliance) was used to pump the reaction solution through the column at a flow rate of $2 \mathrm{~mL} \mathrm{~min}^{-1}$. The empty bed contact time was $0.55 \mathrm{~min}$. This column was rinsed with Milli-Q water at the same flow rate for $30 \mathrm{~min}$ before reaction.

Analysis. Phenol and chlorophenols were analyzed on a Waters HPLC equipped with an Atlantis column $(4.6 \times 250 \mathrm{~mm}, 5 \mu \mathrm{m})$ at a UV wavelength of $280 \mathrm{~nm}$. The separation was performed using an isocratic mobile phase composed of ammonium formate (4 $\mathrm{mM}$ in Milli-Q water) and methanol at a volume ratio of $80 / 20$ and a flow rate of $0.8 \mathrm{~mL} \mathrm{~min}^{-1}$. PDS concentration was analyzed on the same HPLC equipment at a UV wavelength of $230 \mathrm{~nm}$ with a Waters SunFire column $(3.0 \times 150$ $\mathrm{mm}, 5 \mu \mathrm{m}$ ) and an isocratic mobile phase (methanol/0.3\% $\mathrm{H}_{3} \mathrm{PO}_{4}$ at a volume ratio of 20/80 and a

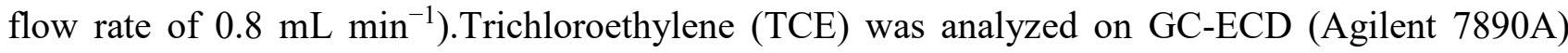
with a DB-1701 column $(30 \mathrm{~m} \times 0.25 \mathrm{~mm} \times 0.25 \mu \mathrm{m})$ following EPA Method 551. Dissolved copper was determined on an ICP-MS (Agilent 7500) with a detection limit of $0.1 \mu \mathrm{g} \mathrm{L}^{-1}$.

For the analysis of adsorbable organic chlorine $(\mathrm{AOCl}), 30 \mathrm{~mL}$ of sample was filtered through tandem activated carbon cartridges (Mitsubishi Chemical Analytech) specifically manufactured for adsorbable organic halogen analysis on a TOX sample preparatory unit. Then, the carbon was calcined at $950{ }^{\circ} \mathrm{C}$ on an Adsorbable Organic Halogen Analyzer (AOX-200, Mitsubishi Chemical Analytech). Chloride ions formed during the calcination was collected into $50 \mathrm{~mL}$ of Milli-Q water. The chloride concentration was determined using a Dionex 1600 IC analyzer equipped with a 
conductivity detector and an AS-15 column which was eluted isocratically with a $30 \mathrm{mM} \mathrm{KOH}$ solution.

To identify degradation products of 2,4-DCP, both GC/MS and HPLC-UV were used. Before GC/MS analysis, $50 \mathrm{~mL}$ of sample was extracted with $1.5 \mathrm{~mL}$ of dichloromethane. The extracts were analyzed on a GC/MS (Agilent7890/5975C) equipped with a DB-1701 column (30 $\mathrm{m} \times 0.25$ $\mathrm{mm} \times 0.25 \mu \mathrm{m}$ ) in EI mode using a full scan range of $40-400 \mathrm{~m} / \mathrm{z}$ (splitless; injector temp.: $280{ }^{\circ} \mathrm{C}$; oven temp.: $50{ }^{\circ} \mathrm{C}$ held for $5 \mathrm{~min}$ then ramped to $250{ }^{\circ} \mathrm{C}$ at $5{ }^{\circ} \mathrm{C} \mathrm{min}^{-1}$; auxiliary temp.: $270{ }^{\circ} \mathrm{C}$ ). The retention times of the compounds generated during the oxidation were compared with those of carboxylate standards on a Waters HPLC-UV $(210 \mathrm{~nm})$ equipped with an XBridge column (4 mm $\times 150 \mathrm{~mm}, 5 \mu \mathrm{m}$ ). An isocratic mobile phase (methanol/0.3\% phosphoric acid at the volume ratio of 20/80 and theflow rate of $0.8 \mathrm{~mL} \mathrm{~min}^{-1}$ ) was used for separation. The presence of these carboxylates was further confirmed with GC/MS after methylation. Conditions of the methylation and the GC/MS analysis were described in the Supporting Information.

Surface interactions between PDS and $\mathrm{CuO}$ particles were characterized with ATR-FTIR and confocal Raman, following similar procedures to our previous work (Text S1, SI). ${ }^{21}$

\section{RESULTS AND DISCUSSION}

PDS activation with metal oxides for 2,4-DCP degradation. The efficiency of seven metal oxides (i.e., $\mathrm{Fe}_{2} \mathrm{O}_{3}, \mathrm{MnO}_{2}, \mathrm{CuO}, \mathrm{ZnO}, \mathrm{TiO}_{2}, \mathrm{MoO}_{3}$ and $\mathrm{CeO}_{2}$ ) to activate PDS for the degradation of 2,4-DCP was compared (Figure 1). 


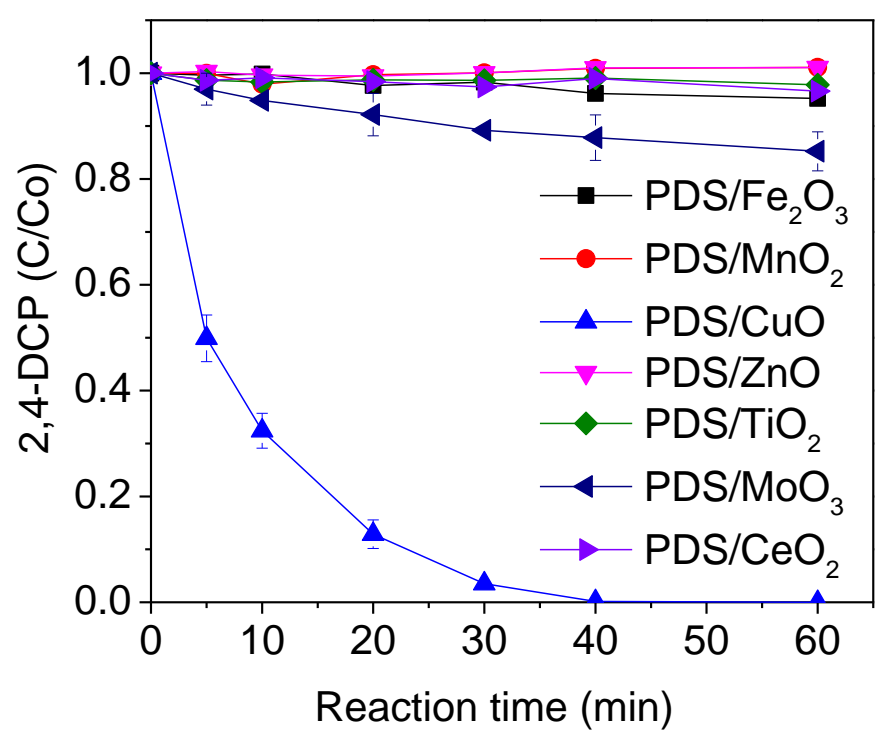

Figure 1. 2,4-DCP removal in PDS solution activated by metal oxides. Conditions: $[\mathrm{PDS}]_{\mathrm{o}}=40 \mu \mathrm{M}$, $[2,4-\mathrm{DCP}]_{\mathrm{o}}=5 \mu \mathrm{M}$, oxide dose $=200 \mathrm{mg} \mathrm{L}^{-1}, \mathrm{pH}=5.8, \mathrm{~T}=20^{\circ} \mathrm{C}$, error bars representing the deviation of three replicates.

PDS alone was unreactive toward 2,4-DCP (Figure S1, SI). Complete removal of 2,4-DCP was achieved in 40 minutes with PDS/CuO coupled process. In contrast, $15 \%$ of 2,4-DCP was removed in $\mathrm{PDS} / \mathrm{MoO}_{3}$, and less than 5\% was removed when PDS was activated by other metal oxides after 1 h of reaction. No noticeable adsorption of 2,4-DCP on $\mathrm{CuO}$ or $\mathrm{MoO}_{3}$ was observed (Figure S1, SI), indicating that the 2,4-DCP was degraded in PDS/CuO and PDS/ $\mathrm{MoO}_{3}$ but not adsorbed on oxide particles. The result clearly show that $\mathrm{CuO}$ is the most active among the metal oxides tested for PDS activation, although its surface area is one of the lowest (Table $\mathrm{S} 1, \mathrm{SI}$ ). $\mathrm{MoO}_{3}$ is much less active than $\mathrm{CuO} . \mathrm{Fe}_{2} \mathrm{O}_{3}, \mathrm{MnO}_{2}, \mathrm{ZnO}, \mathrm{TiO}_{2}$, and $\mathrm{CeO}_{2}$ have very low capacity in PDS activation under our experimental conditions.

$\mathrm{Cu}^{2+}$ was reported to donate one electron to PDS, thus inducing PDS decomposition into sulfate and sulfate radical. ${ }^{24}$ However, this process is very slow, making effective degradation of water pollutants nearly impossible. For example, only $2 \%$ of PDS can be decomposed at a PDS/Cu ${ }^{2+}$ molar 
ratio of $1: 1$ in $10 \mathrm{~h}^{25} \mathrm{In}$ this $\mathrm{PDS} / \mathrm{CuO}$ oxidation, $\mathrm{Cu}^{2+}$ leached from $\mathrm{CuO}$ after $1 \mathrm{~h}$ reaction was 0.68 $\mathrm{mg} \mathrm{L}^{-1}(10.7 \mu \mathrm{M}) . \mathrm{Cu}^{2+}$ in the range of $2-80 \mu \mathrm{M}$ had negligible activity in promoting PDS oxidation of 2,4-DCP (Figure S2, SI). This finding confirms that $\mathrm{CuO}$ particles are responsible for the improved PDS oxidation. The trace $\mathrm{Cu}^{2+}$ leached from $\mathrm{CuO}$ had no significant effect. In the presence of $\mathrm{CuO}$ alone, PDS remained stable in solution, but appreciable decomposition of PDS occurred when 2,4-DCP was introduced into the PDS/CuO suspension (Figure S3, SI). It is likely that the PDS is activated by $\mathrm{CuO}$, but this activation is not strong enough to lead to PDS decomposition into radicals. When 2,4-DCP was present in solution, either in the solution or on the $\mathrm{CuO}$ surface, it probably readily reacted with the surface activated PDS, leading to PDS consumption.

To the best of our knowledge, it is the first work reporting the high activity of $\mathrm{CuO}$ in heterogeneously promoting the oxidation potential of PDS. Further experiments were carried out on the PDS/CuO coupled process to determine influencing factors, durability, kinetics, and mechanism, which could be useful to evaluate the application potential of this PDS activation method.

Influence of calcination temperature in the preparation of CuO. The $\mathrm{CuO}$ particles were prepared at different calcination temperatures ranging from 300 to $650{ }^{\circ} \mathrm{C}$. These $\mathrm{CuO}$ particles were in the monoclinic $\mathrm{CuO}$ phase (Figure S4, SI). Their specific surface area, activity in promoting PDS oxidation of 2,4-DCP, and copper leaching in the reaction are depicted in Figure S5A (SI). Significant decrease of the specific surface area of $\mathrm{CuO}$ particles (from 0.96 to $0.075 \mathrm{~m}^{2}$ $\mathrm{g}^{-1}$ ) was observed with increasing calcination temperature. The 2,4-DCP degradation rates with PDS/CuO oxidation, which were fitted with a pseudo-first order model, decreased by about 20 times when the calcination temperature increased from 300 to $650{ }^{\circ} \mathrm{C}$. The corresponding copper leaching was reduced from 0.99 to $0.42 \mathrm{mg} \mathrm{L}^{-1}$. The 2,4-DCP degradation rates were linearly correlated to the 
surface area of these $\mathrm{CuO}$ particules (coefficient $=1.449 \mathrm{~min}^{-1} \mathrm{~m}^{-2}$ ) (Figure $\left.\mathrm{S} 5 \mathrm{~B}, \mathrm{SI}\right)$. The copper leaching increased with surface area but did not follow a linear relationship. The calcination temperature of $450{ }^{\circ} \mathrm{C}$ inducing moderate activity and copper leaching was selected as a trade-off condition of $\mathrm{CuO}$ preparation for the rest of our experiments.

Influence of pH. Figure 2 shows the variation of 2,4-DCP degradation rate and copper leaching during $\mathrm{PDS} / \mathrm{CuO}$ oxidation within the $\mathrm{pH}$ range of 4.2-8.0.

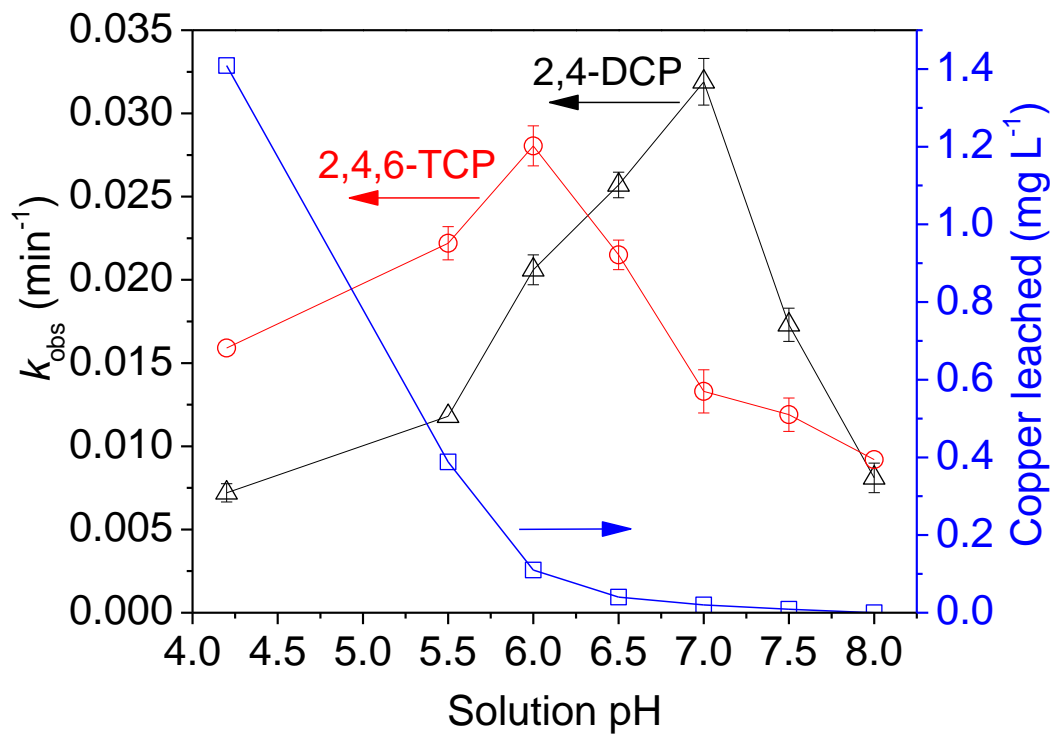

Figure 2. Influences of $\mathrm{pH}$ on the degradation rates of 2,4-DCP and 2,4,6-TCP in $\mathrm{PDS} / \mathrm{CuO}$ oxidation and copper leaching in 2,4-DCP degradation. Conditions: $[\mathrm{PDS}]_{\mathrm{o}}=20 \mu \mathrm{M}$, $[2,4-\mathrm{DCP}]_{\mathrm{o}} /[2,4,6-\mathrm{TCP}]_{\mathrm{o}}=5 \mu \mathrm{M}, \mathrm{CuO}$ dose $=200 \mathrm{mg} \mathrm{L}^{-1}$, reaction time $=20 \mathrm{~min}, \mathrm{~T}=20$ ${ }^{\circ} \mathrm{C}$, error bars representing the deviation of three replicates.

The PDS/CuO coupled process achieved the highest 2,4-DCP degradation rate at $\mathrm{pH} 7.0$. The degradation rate decreased when the solution became acidic or alkaline. There was a significant reduction of copper leaching as the $\mathrm{pH}$ was raised from 4.2 to 8.0. At $\mathrm{pH} 7.0$ where the $\mathrm{PDS} / \mathrm{CuO}$ was the most efficient for 2,4-DCP degradation, copper leaching was only $20 \mu \mathrm{g} \mathrm{L}^{-1}$, which is 50 times lower than most drinking water standards (i.e., $1.0-1.3 \mathrm{mg} \mathrm{L}^{-1}$ ). Since the $\mathrm{pH}_{\mathrm{pzc}}$ of $\mathrm{CuO}$ was determined to be around 9.5, the $\mathrm{CuO}$ particles were positively charged in the $\mathrm{pH}$ range of this study. 
It can be assumed that $\mathrm{S}_{2} \mathrm{O}_{8}{ }^{2-}$ in this $\mathrm{pH}$ range can be adsorbed on the positively charged $\mathrm{CuO}$ surface. The $\mathrm{pK}_{\mathrm{a}}$ of 2,4-DCP is $7.89 .{ }^{26}$ At $\mathrm{pH}$ higher than 7.89, over half of 2,4-DCP is deprotonated, which favors electrostatic interaction with the positively charged $\mathrm{CuO}$ surface. However, the 2,4-DCP degradation rate was reduced as the $\mathrm{pH}$ was further raised above 7.0. One possible reason could be that the interaction between deprotonated 2,4-DCP and negatively charged $\mathrm{S}_{2} \mathrm{O}_{8}{ }^{2-}$ species adsorbed on $\mathrm{CuO}\left(\equiv \mathrm{Cu}^{\mathrm{II}} \ldots{ }^{-} \mathrm{O}_{3} \mathrm{SOOSO}_{3}{ }^{-}\right)$is unfavorable. To support this hypothesis, degradation of 2,4,6-trichlorophenol (2,4,6-TCP) was also tested in the same $\mathrm{pH}$ range (Figure 2). The 2,4,6-TCP has a lower $\mathrm{pK}_{\mathrm{a}}(6.23)$ than $2,4-\mathrm{DCP} .{ }^{26}$ If the anticipated reaction mechanism between the pollutant and the adsorbed $\mathrm{S}_{2} \mathrm{O}_{8}{ }^{2-}$ is true, the 2,4,6-TCP should be degraded most efficiently at a lower $\mathrm{pH}$ than 2,4-DCP. As shown in Figure 2, the optimum $\mathrm{pH}$ for the degradation of 2,4,6-TCP in the $\mathrm{PDS} / \mathrm{CuO}$ oxidation system shifted to a lower value (ph 6.0) as compared to 2,4-DCP.

The strong inverse $\mathrm{H}^{+}$-dependency of the degradation rate of 2,4-DCP in PDS/CuO could be related to the degradation pathway, because $\mathrm{OH}^{-}$is needed for the replacement of chlorine atoms from the 2,4-DCP molecule (shown later). Another reason could be similar to that suggested for the adverse impact of $\mathrm{H}^{+}$on PMS activation. ${ }^{4} \mathrm{H}^{+}$would probably form an $\mathrm{H}$-bond with the negatively charged $\mathrm{O}$ in the $\mathrm{S}_{2} \mathrm{O}_{8}{ }^{2-}$ molecule and thus inhibit its interaction with positively charged $\mathrm{Cu}$ II of $\mathrm{CuO}$.

Efficiency and durability in continuous-flow reaction. Long-term performance is a critical factor to be considered for potential application of the PDS/CuO coupled process. A $\mathrm{CuO}$ particle packed column $(1.1 \mathrm{~mL})$ was used to test the efficiency and durability of the coupled process in a continuous-flow reaction. An experiment conducted in the absence of PDS $(20 \mu \mathrm{M}$ of $2,4-\mathrm{DCP}$ and $\mathrm{pH}$ 5.8) showed no adsorption of 2,4-DCP on $\mathrm{CuO}$ particles of the column. Figure 3 shows 2,4-DCP degradation, remaining AOCl and copper leaching over a $750 \mathrm{~h}$ continuous-flow reaction. 


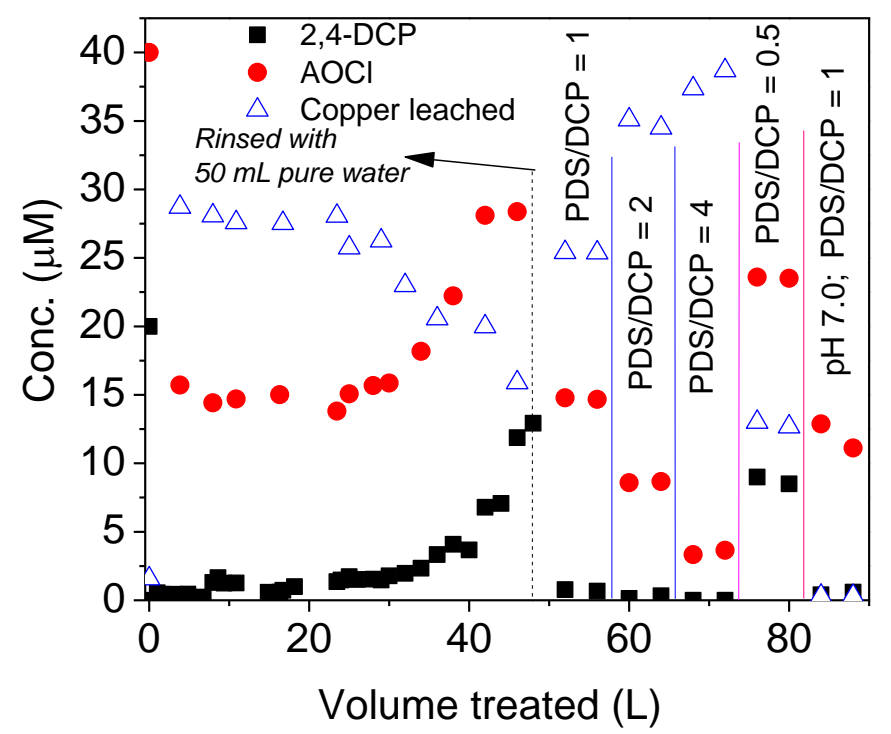

Figure 3. Concentrations of 2,4-DCP, $\mathrm{AOCl}$ and leached $\mathrm{Cu}^{2+}$ in the effluent of a continuous-flow reaction. Conditions: inflow concentration of 2,4-DCP $=20 \mu \mathrm{M}$, inflow PDS concentration depends on the PDS/2,4-DCP molar ratio as indicated inside the graph, $\mathrm{pH}=5.8$ (without buffer addition) if not indicated in the graph, flow rate $=2 \mathrm{~mL} \mathrm{~min}^{-1}$, empty-bed contact time $=0.55 \min , \mathrm{T}=20^{\circ} \mathrm{C}$.

The influent with PDS/2,4-DCP molar ratio of 1 was applied during the first phase of the experiment (from 0 to $48 \mathrm{~L}$ of treated influent volume). A steady 2,4-DCP removal and $\mathrm{AOCl}$ removal (over $90 \%$ and $60 \%$, respectively) were achieved for the first $30 \mathrm{~L}$ of influent followed by a gradual decrease of the removal to $35 \%$ and $30 \%$ respectively at the end of this phase. Then, the $\mathrm{CuO}$ column was rinsed with $50 \mathrm{~mL}$ of Milli-Q water at the same flow rate. The next phase of the experiment (from 49 to $58 \mathrm{~L}$ of treated influent volume in Figure 3) was started at the same PDS/2,4-DCP molar ratio of 1. Interestingly, both 2,4-DCP and AOCl removal were recovered after the Milli-Q water rinsing. This finding indicates that the decline of PDS/CuO oxidation efficiency at the end of the first phase (first $48 \mathrm{~L}$ ) is possibly due to weak adsorption of solutes, such as 2,4-DCP degradation intermediates, on $\mathrm{CuO}$ particles. As the PDS/2,4-DCP molar ratio was raised to 2 (from 59 to $66 \mathrm{~L}$ of treated influent volume in Figure 3) and 4 (from 67 to $74 \mathrm{~L}$ of treated influent volume), the 2,4-DCP was completely removed, and the AOCl removal was increased from $80 \%$ to $90 \%$. 
When the PDS/2,4-DCP molar ratio was reduced to 0.5 (from 75 to $82 \mathrm{~L}$ of treated influent volume in Figure 3), the 2,4-DCP removal was about 55\%, and the $\mathrm{AOCl}$ removal decreased to $15 \%$. During thefinal phase of the experiment (from 83 to $90 \mathrm{~L}$ of treated influent volume in Figure 3), the $\mathrm{pH}$ of the influent with the PDS/2,4-DCP molar ratio of 1 was adjusted to 7.0. The 2,4-DCP was nearly completely removed, and the average AOCl removal was about $70 \%$.

The concentration of leached copper in the effluent increased with PDS dosage. It was significantly reduced to less than $1.0 \mu \mathrm{M}$ when the $\mathrm{pH}$ of the influent was raised to 7.0 , which is consistent with the result shown in Figure 2. In addition, no decline of the PDS/CuO oxidation efficiency was observed after the first phase of the experiment. In the second to last phase of the experiment $(\mathrm{PDS} / 2,4-\mathrm{DCP}=0.5)$, less degradation intermediates might have been produced from 2,4-DCP due to reduced PDS dosage, which could mitigate the adsorption of the degradation intermediates onto the $\mathrm{CuO}$ particles or lead to desorption of previously adsorbed ones. The neutral $\mathrm{pH}$ in the last phase of the experiment could have similar effects, as the adsorption of compounds having carboxyl/hydroxyl groups on metal oxides usually decreases with increasing $\mathrm{pH} .{ }^{27}$

The results of the continuous-flow reaction indicate that 1 ) the $\mathrm{CuO}$ prepared has durable activity in PDS activation for 2,4-DCP degradation, on the understanding that periodical rinsing can be applied to eliminate adsorbed oxidation products from the $\mathrm{CuO} ; 2$ ) the $\mathrm{PDS} / \mathrm{CuO}$ has a high oxidation efficiency, removing over $90 \%$ of $2,4-\mathrm{DCP}$ at the PDS/CuO molar ratio of 1 and over $90 \%$ of $\mathrm{AOCl}$ at the $\mathrm{PDS} / \mathrm{CuO}$ molar ratio of 4 in a short contact time of $0.55 \mathrm{~min}$; and 3) copper leaching can be reduced to a low level if the PDS/CuO process is operated at neutral $\mathrm{pH}$. In operations where rinsing with clean water is impractical such as in situ treatment of groundwater, intermittent 
operation without introduction of PDS might be a choice to recover the efficiency of the PDS/CuO, which can be tested in future studies.

Influence of radical scavengers and ionic strength. Sulfate radical is usually considered to be the actual oxidant species in activated PDS processes. At neutral and alkaline pHs, hydroxyl radical can also be generated due to the reaction of sulfate radical with $\mathrm{OH}^{-}$. The two radical species react very rapidly with ethanol $\left(k \cdot \mathrm{OH}=(1.2-2.8) \times 10^{9} \mathrm{M}^{-1} \mathrm{~s}^{-1} ; k \cdot\right.$ sO4- $=(1.6-7.8) \times 10^{7}$ $\left.\mathrm{M}^{-1} \mathrm{~s}^{-1}\right) .{ }^{6}$ For example, 2,4-DCP degradation by sulfate radical generated in $\mathrm{Co}^{2+} / \mathrm{PMS}$ coupled process was nearly completely scavenged at the ethanol/PMS molar ratio of 1000 . We noticed that ethanol at a dose up to 1000 times of PDS's molar concentration had no influence on 2,4-DCP degradation in the PDS/CuO coupled process (Figure 4), which indicates that PDS activation by $\mathrm{CuO}$ does not follow the sulfate radical generation mechanism.

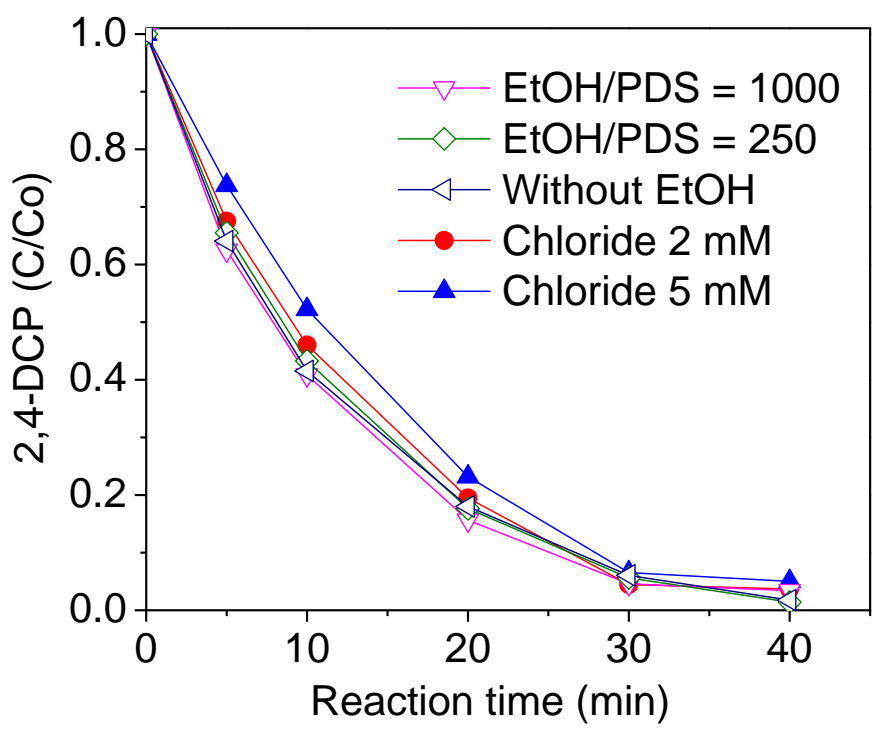

Figure 4. Influence of ethanol and chloride on 2,4-DCP degradation in the PDS/CuO oxidation. Conditions: $[\mathrm{PDS}]_{\mathrm{o}}=20 \mu \mathrm{M},[2,4-\mathrm{DCP}]_{\mathrm{o}}=5 \mu \mathrm{M}, \mathrm{CuO}$ dose $=200 \mathrm{mg} \mathrm{L}^{-1}$, initial $\mathrm{pH}$ was adjusted with diluted $\mathrm{NaOH} / \mathrm{HNO}_{3}$ to $5.8, \mathrm{~T}=20{ }^{\circ} \mathrm{C}$. 
Chloride ions can be oxidized by sulfate radical to $\mathrm{Cl} \cdot\left(k \cdot \mathrm{sO}_{-}=2.0 \times 10^{8} \mathrm{M}^{-1} \mathrm{~s}^{-1}\right)$ which rapidly combines with another chloride in water forming $\mathrm{Cl}_{2} 2^{-}$(chlorine radical). ${ }^{22}$ The reducing potential of chlorine radical $\left(E_{\mathrm{Cl} 2_{-} / 2 \mathrm{Cl}-}^{o}=2.09 \mathrm{~V}\right)$ is lower than sulfate radical $\left(E^{\mathrm{o}} \mathrm{SO}_{-/ / \mathrm{SO} 42-}=2.5-3.1 \mathrm{~V}\right)$. The influence of chloride ions on the pollutant degradation rate during sulfate radical oxidation is dependent on the target pollutant. ${ }^{28}$ For example, iopromide degradation rate by sulfate radical was reduced by $50 \%$ in the presence of $2 \mathrm{mM}$ chloride. ${ }^{21}$ In contrast, it was reported that the degradation rate of 2,4-DCP was improved by the presence of chloride during sulfate radical oxidation, ${ }^{22}$ probably because chlorine radical is more reactive with 2,4-DCP than its degradation intermediates as compared with the relatively nonselective sulfate radical. Figure 4 shows that the presence of 2 and $5 \mathrm{mM}$ chloride slightly reduced the 2,4-DCP degradation rate (by about 9\%), which could be caused by the negative effect of increased ionic strength as indicated in Figure S6 (SI). This result also suggests that sulfate radical is not the oxidant species responsible for 2,4-DCP degradation in the PDS/CuO coupled process.

Because the PDS/CuO is not a sulfate radical generation process, the 2,4-DCP degradation should be related to surface activation of PDS or 2,4-DCP or both of them. Under slightly acidic conditions, PDS, 2,4-DCP, and $\mathrm{CuO}$ are negatively, neutrally, and positively charged, respectively. The increase of the ionic strength will reduce the zeta potential of the $\mathrm{CuO}$ particles through compressing the thickness of the electric double layer. Figure S6 (SI) shows that the 2,4-DCP degradation rate at high ionic strength (represented with $\mathrm{NaClO}_{4}$ concentration) was much lower than that at low ionic strength. The 2,4-DCP degradation rate logarithmically decreased as the $\mathrm{NaClO}_{4}$ concentration was increased from 10 to $100 \mathrm{mM}$. The result suggests that the reaction is dominated by the interaction of two oppositely charged species, i.e., $\mathrm{S}_{2} \mathrm{O}_{8}{ }^{2-}$ and positively charged $\mathrm{CuO}$. Taking the significantly 
reduced reactivity of deprotonated 2,4-DCP (favoring interaction with positively charged $\mathrm{CuO}$ ) during the PDS/CuO oxidation also into account (Figure 2), the promoted 2,4-DCP oxidation cannot be ascribed to surface activation of 2,4-DCP or simultaneous activation of 2,4-DCP and PDS. Surface activation of PDS on CuO particles is most likely the only reason.

Kinetics. The kinetic study was carried out at pH 5.8. In an excess of PDS (20-200 $\mu \mathrm{M})$, the degradation rate of 2,4-DCP (with an initial concentration of $5 \mu \mathrm{M}$ ) below $60 \%$ removal was well fitted with a pseudo-first order reaction model at each given PDS concentration (Figure 5A). Plotting $\ln \left(k_{o b s}\right)$ vs $\ln \left([\mathrm{PDS}]_{\mathrm{o}}\right)$ yielded a linear curve with a slope approximating 0.335 . The decomposition rate of PDS was independent of the 2,4-DCP concentration which was in excess (Figure 5B). The $\ln \left(k_{o b s}\right)$ of PDS decomposition during 2,4-DCP degradation was linearly correlated to $\ln \left(\left[\mathrm{Cu}^{\mathrm{II}}\right]_{\text {surf }}\right)$ $\left(\left[\mathrm{Cu}^{\mathrm{II}}\right]_{\text {surf }}\right.$ is the $\mathrm{CuO}$ dose $\left(\mathrm{g} \mathrm{L}^{-1}\right)$ multiplied by the density of surface $\mathrm{Cu}$ II of $\mathrm{CuO}$ i.e., $\left.3.3 \mu \mathrm{mol} \mathrm{g}^{-1}\right)$ with a slope of 0.688 (Figure 5C).

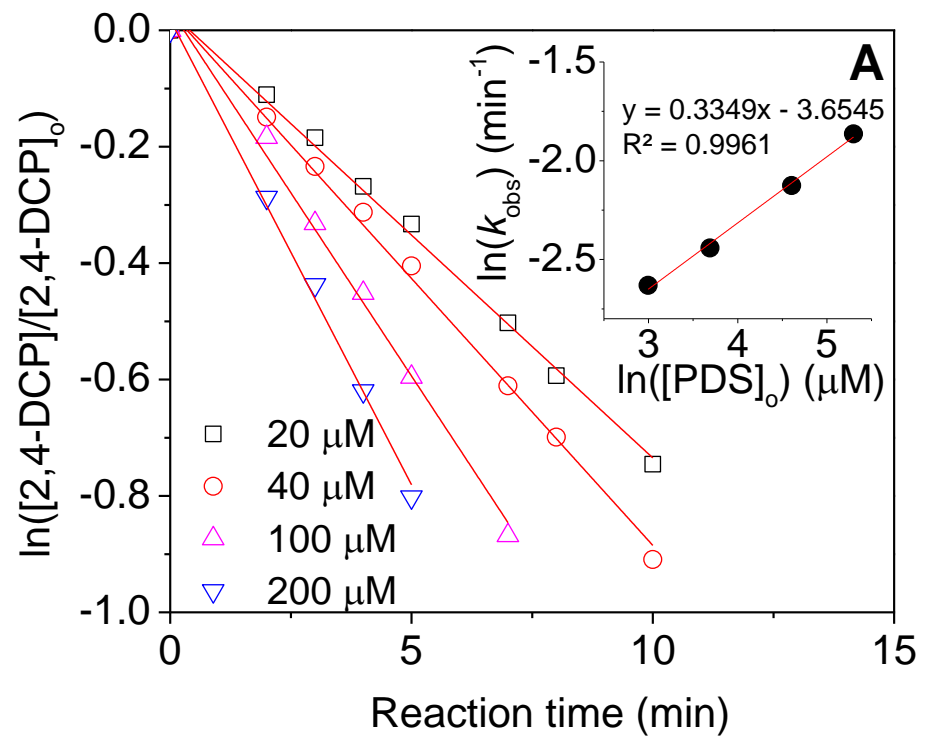



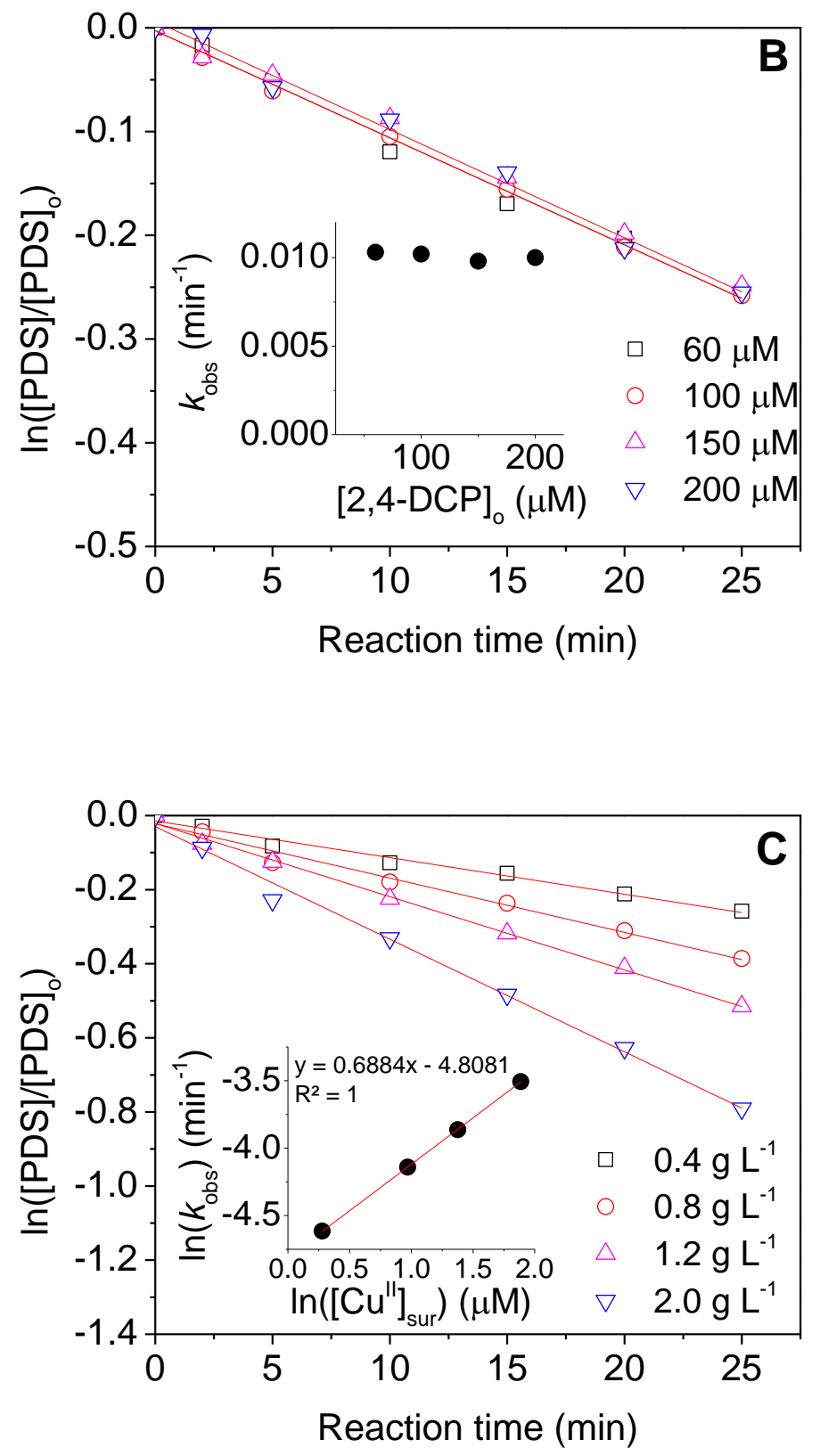

Figure 5. Influences of PDS dose on 2,4-DCP decomposition $\left(\mathrm{A}\right.$ : $[2,4-\mathrm{DCP}]_{\mathrm{o}}=5 \mu \mathrm{M}, \mathrm{CuO}$ dose $=$ $400 \mathrm{mg} \mathrm{L}^{-1}$ ), 2,4-DCP dose on PDS decomposition (B: $[\mathrm{PDS}]_{\mathrm{o}}=20 \mu \mathrm{M}, \mathrm{CuO}$ dose $=400$ $\left.\mathrm{mg} \mathrm{L}^{-1}\right)$, and $\mathrm{CuO}$ dose on PDS decomposition $\left(\mathrm{C}:[\mathrm{PDS}]_{\mathrm{o}}=20 \mu \mathrm{M},[2,4-\mathrm{DCP}]_{\mathrm{o}}=10 \mu \mathrm{M}\right)$ during PDS/CuO oxidation. Conditions: $\mathrm{pH}=5.8, \mathrm{~T}=20^{\circ} \mathrm{C}$.

It is clear that the dosages of $\mathrm{CuO}$ and PDS have significant influence on the reaction. PDS activation by $\mathrm{CuO}$ is the reaction rate-limiting for the PDS/CuO oxidation of 2,4-DCP. Since the reaction involves three species, i.e., PDS, surface $\mathrm{Cu}^{\mathrm{II}}$ and 2,4-DCP, the overall reaction rate $(v)$ can be expressed in eq $1 . k$ is the apparent reaction rate constant; $\mathrm{n} 1, \mathrm{n} 2$ and $\mathrm{n} 3$ are reaction orders in 
PDS, surface $\mathrm{Cu}^{\mathrm{II}}$ and DCP concentrations, respectively. According to the experimental result, $0.335,0.688$ and 0 can be assigned to $\mathrm{n} 1, \mathrm{n} 2$ and $\mathrm{n} 3$, respectively. Values of $k\left(0.062 \pm 0.003 \mathrm{~min}^{-1}\right)$ were calculated with eq 2 and the data of Figure 5C. Then, the overall reaction rate under our experimental conditions can be expressed in eq 3 with a unit of $\mu \mathrm{M} \mathrm{min}^{-1}$. The overall reaction order (i.e., $\mathrm{n} 1+\mathrm{n} 2$ ) is close to 1 , meaning that the overall reaction rate is in first order.

$v=\frac{-\mathrm{d}[\mathrm{PDS}]}{\mathrm{dt}}=\frac{-\mathrm{d}[\mathrm{DCP}]}{\mathrm{dt}}=k[\mathrm{PDS}]^{\mathrm{n} 1}[\mathrm{Cu}]_{\text {surf }}^{\mathrm{II}}[\mathrm{DCP}]^{\mathrm{n} 3}$

$\frac{-\mathrm{d}[\mathrm{PDS}]}{\mathrm{dt}}=k[\mathrm{PDS}]^{0.335}\left[\mathrm{Cu}^{\mathrm{II}}\right]_{\text {surf }}^{0.688}=k_{\text {obs }}[\mathrm{PDS}]$

$v=0.062[\mathrm{PDS}]^{0.335}\left[\mathrm{Cu}^{\mathrm{II}}\right]_{\text {surf }}^{0.688}$

PDS activation mechanism. It was shown in our previous studies that ATR-FTIR and confocal Raman are useful protocols for in situ characterization of solute-solid surface interactions in water. ${ }^{21,29}$ Characterization of PDS-CuO interaction using the two techniques showed that there were neither shift of the typical vibration bands of PDS nor new peak formation (Figure S7 and S8, SI), which means that 1) the interaction between PDS and $\mathrm{CuO}$ does not form a chemical bond which can change the vibration frequencies of the adsorbed PDS molecules, and 2) there are no decomposition intermediates (like peroxo species) of PDS on the $\mathrm{CuO}$ surface. The first conclusion can also explain the influence of ionic strength on the PDS/CuO (Figure S6, SI). If the PDS strongly interacted with $\mathrm{CuO}$, the increase of ionic strength would have no influence on the PDS/CuO oxidation of 2,4-DCP, because the increase of ionic strength does not influence inner-sphere interactions (covalent bonding or a combination of covalent and ionic bonding) between the particle's surface and the solute. On the contrary, the increase of ionic strength significantly influences outer-sphere interactions (electrostatic bonding) in both equilibrium and kinetics. ${ }^{30}$ As 
shown for the PMS activation in our previous work, the inner-sphere coordination between PMS and the surface $\mathrm{Cu}(\mathrm{II})$ sites of $\mathrm{CuO}$ caused significant dissolution of $\mathrm{CuO}$ even at neutral $\mathrm{pHs} .{ }^{21}$ The low copper leaching in the PDS/CuO coupled process at neutral $\mathrm{pH}$ (Figure 2) can also be interpreted with the weak PDS-CuO interaction. The second conclusion is consistent with the fact that PDS was nearly not decomposed on the $\mathrm{CuO}$ surface in the absence of 2,4-DCP (Figure S3, SI).

Unlike $\mathrm{CuO}$ activated PMS and base activated $\mathrm{PDS},{ }^{3,21}$ no gas bubble was formed in the PDS/CuO system at a high PDS concentration (200 mM) (not shown), indicating again that the PDS activation mechanism is different from those processes. Furman et al. reported that superoxide $\left(\mathrm{O}_{2}{ }^{{ }^{*}}\right)$ was produced in base activated $\mathrm{PDS}^{3}$ Superoxide can reduce highly oxidized compounds like hexachloroethane. However, superoxide cannot exist in the PDS/CuO system, because traces pf $\mathrm{Cu}(\mathrm{II})$ can rapidly dismutate superoxide into oxygen and hydrogen peroxide. ${ }^{31}$ Since no gas was formed from the PDS/CuO suspension, it can be confirmed that superoxide was not produced.

When activated by $\mathrm{CuO}$, PDS is not"directly" dissociated, because significant decomposition of PDS only occurred when 2,4-DCP coexisted in the solution but not in the absence of 2,4-DCP (Figure S3, SI), indicating that an electron donor is needed for the decomposition of activated PDS. It is reasonable to propose that the outer-sphere interaction between the positively charged $\mathrm{CuO}$ surface and the PDS anion induced some slight rearrangement of the PDS electrons. This interaction is not strong and thus does not form chemical bonds. However, it already makes the PDS much more reactive toward 2,4-DCP, thus leading to significant PDS decomposition in the presence of 2,4-DCP. The outer-sphere interaction between PDS and $\mathrm{CuO}$ was indirectly proved in this work. In situ X-ray adsorption spectroscopy (XAS) usually can provide direct evidence for outer-sphere and 
inner-sphere interactions between metal oxides and oxyanions, ${ }^{32,33}$ which could be applied to verify this PDS-CuO interaction in future studies.

Comparison with sulfate radical oxidation. $\mathrm{PMS} / \mathrm{Co}^{2+}$, a well-known sulfate radical generation process, was compared with the PDS/CuO coupled process for 2,4-DCP degradation at the same oxidant dosages. The redox couple of $\mathrm{Co}^{2+} / \mathrm{Co}^{3+}$ was reported to be efficient in initiating PMS decomposition into sulfate radicals. ${ }^{6} \mathrm{Co}^{2+}(3 \mu \mathrm{M})$ in the $\mathrm{PMS} / \mathrm{Co}^{2+}$ process was dosed at a similar concentration to surface $\mathrm{Cu}^{\mathrm{II}}\left(3.3 \mu \mathrm{M}\right.$ at the $\mathrm{CuO}$ dosage of $\left.1.0 \mathrm{~g} \mathrm{~L}^{-1}\right)$ in the $\mathrm{PDS} / \mathrm{CuO}$ process. $4 \mathrm{mM}$ of chloride ions were also introduced into the reaction solution as it ubiquitously exists in water. In order to identify degradation products, a high 2,4-DCP concentration $(500 \mu \mathrm{M})$ was applied. The reaction time was extended long enough to ensure complete consumption of the oxidants. Figure 6 shows that, at the oxidant/2,4-DCP molar ratio of 1, the PDS/CuO coupled process achieved $90 \%$ 2,4-DCP removal, while the $\mathrm{PMS} / \mathrm{Co}^{2+}$ process removed only $24 \%$ of 2,4-DCP. When the ratio was raised to 4 , the 2,4-DCP was nearly completely removed by PDS/CuO oxidation compared with $55 \%$ removal by $\mathrm{PMS} / \mathrm{Co}^{2+}$ oxidation. The PDS/CuO process showed a much higher 2,4-DCP degradation capacity than the sulfate radical oxidation process even at 4 times lower oxidant dosage. Control experiments conducted with PDS alone and PMS alone removed less than $5 \%$ 2,4-DCP (data not shown). 


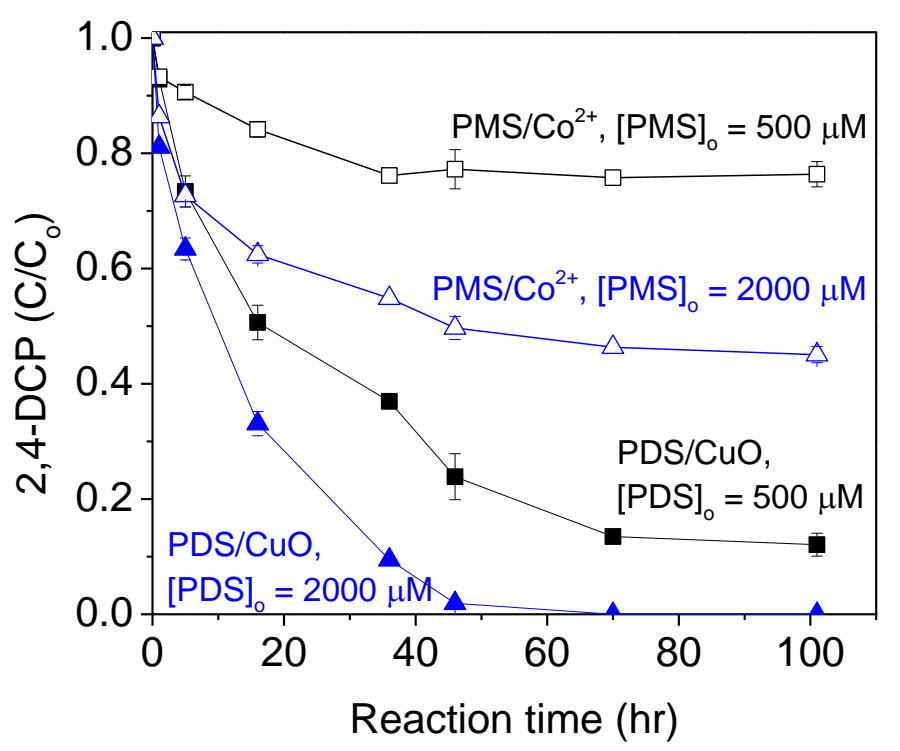

Figure 6. Comparison of $\mathrm{PDS} / \mathrm{CuO}$ with $\mathrm{Co}^{2+} / \mathrm{PMS}$ for 2,4-DCP degradation. Conditions: $[2,4-\mathrm{DCP}]_{\mathrm{o}}=500 \mu \mathrm{M}, \mathrm{CuO}$ dose $=1 \mathrm{~g} \mathrm{~L}^{-1},\left[\mathrm{Co}^{2+}\right]_{\mathrm{o}}=3 \mu \mathrm{M}, \quad\left[\mathrm{Cl}^{-}\right]_{\mathrm{o}}=4 \mathrm{mM}, \quad$ initial $\mathrm{pH}$ was adjusted with diluted $\mathrm{NaOH} / \mathrm{HNO}_{3}$ to $5.8, \mathrm{~T}=20{ }^{\circ} \mathrm{C}$, error bars representing the deviation of three replicates.

Figure S9 (SI) shows GC/MS chromatograms of 2,4-DCP after reaction in the two oxidation processes. 2-chloro-1,4-hydroquinone and 2-chloro-benzoquinone were major degradation products after PDS/CuO oxidation at the PDS/2,4-DCP molar ratio of 1 (Figure S9A, SI). These products were significantly reduced, when the molar ratio was raised to 4. Oxalate and maleic acid were proposed to be carboxylate products in $\mathrm{PDS} / \mathrm{CuO}$ oxidation as the retention times of the product peaks detected on HPLC-UV (210 nm) (Figure S10A, SI) were exactly the same as the standards. The presence of the two carboxylates was further confirmed with GC/MS, when the 2,4-DCP sample oxidized with low PDS dosage $(\mathrm{PDS} / 2,4-\mathrm{DCP}=1)$ was extracted under acidic conditions and methylated (Figure S10B, SI). For high PDS dosage (PDS/2,4-DCP = 4), only oxalate with increased concentration appeared (Figure S10A, SI). The result indicates that the two major degradation products of 2,4-DCP were further degraded into carboxylates, and the final degradation products could be oxalate in excess of PDS. Comparing 2,4-DCP products generated in the two oxidation 
systems, it was noticed that despite the two monochlorinated products identified in PDS/CuO oxidation, the $\mathrm{PMS} / \mathrm{Co}^{2+}$ process (especially at the $\mathrm{PMS} / 2,4-\mathrm{DCP}$ molar ratio of 4 ) generated highly chlorinated products (i.e., 1,1,3,3-pentachloropropanone, 1,1,3,3-tetrachloropropanone, 2,2,4-trichloro-1,3-cyclopentenedione and 2,4,6-trichlorophenol), among which 2,4,6-trichlorophenol was observed in high peak intensity even at the PMS/2,4-DCP molar ratio of 1 (Figure S9A and S9B, SI). The production of all these additionally formed highly chlorinated products increased as the PMS/2,4-DCP molar ratio was raised from 1 to 4 (Figure S9B, SI). The formation of these highly chlorinated products can be ascribed to reactions of 2,4-DCP

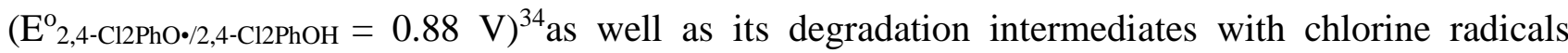
$\left(\mathrm{E}^{\mathrm{O}} \mathrm{Cl}_{2} \cdot{ }^{-} / 2 \mathrm{Cl}^{-}=2.09 \mathrm{~V}\right)^{22}$ which were generated from the oxidation of chloride ions by sulfate radicals in the PMS $/ \mathrm{Co}^{2+}$ process. The result indicates that unlike sulfate radical the $\mathrm{CuO}$ surface activated PDS is not strong enough to oxidize chloride ions into reactive radical species. Therefore, the second advantage of PDS/CuO oxidation over sulfate radical oxidation is the absence of highly chlorinated product formation. The $\mathrm{PDS} / \mathrm{CuO}$ could be more preferable than sulfate radical generating processes in reducing oxidant cost by achieving a high pollutant degradation rate while simultaneously avoiding the formation of more hazardous products.

The formation of 2-chlorobenzoquinone from 2,4-DCP needs two electron abstraction by the oxidant (eq 4). Its further transformation to maleic acid and oxalic acid requires abstraction of more electrons by the oxidant. Since over $90 \%$ 2,4-DCP was degraded at the PDS/2,4-DCP molar ratio of 1 and all three products were present (Figure S9 and S10, SI), it can be speculated that all of the oxidation capacity of PDS (i.e., two electron abstraction from organics by one PDS (eq 5)) was utilized in the PDS/CuO process. It is more efficient than the alkaline activated PDS process (one 
sulfate radical generated from two PDS for one electron abstraction from organics (eq 6)) which is presently one of the most important PDS activation methods for ISCO. At least half of the oxidation capacity was also wasted in the $\mathrm{Fe}^{2+}$ activated PDS which is usually proposed for wastewater treatment (eq 7).

$$
\begin{aligned}
& \mathrm{C}_{6} \mathrm{H}_{4} \mathrm{Cl}_{2} \mathrm{O}+\mathrm{OH}^{-}-2 \mathrm{e} \rightarrow \mathrm{C}_{6} \mathrm{H}_{3} \mathrm{ClO}_{2}+2 \mathrm{H}^{+}+\mathrm{Cl}^{-} \\
& \mathrm{S}_{2} \mathrm{O}_{8}{ }^{2-}+2 \mathrm{e} \rightarrow 2 \mathrm{SO}_{4}{ }^{2-} \\
& 2 \mathrm{~S}_{2} \mathrm{O}_{8}{ }^{2-}+2 \mathrm{H}_{2} \mathrm{O} \rightarrow 3 \mathrm{SO}_{4}{ }^{2-}+\mathrm{SO}_{4}{ }^{--}+\mathrm{O}_{2}{ }^{--}+4 \mathrm{H}^{+} \\
& \mathrm{S}_{2} \mathrm{O}_{8}{ }^{2-}+\mathrm{Fe}^{2+} \rightarrow \mathrm{SO}_{4}{ }^{2-}+\mathrm{SO}_{4}{ }^{--}+\mathrm{Fe}^{3+}
\end{aligned}
$$

Selectivity of the PDS/CuO oxidation. The PDS/CuO coupled process was also tested for the degradation of trichloroethylene (TCE), $p$-chlorobenzoic acid ( $p$-CBA), iopromide, phenol and three chlorophenols (Figure S11, SI). The $p$-CBA is a well-known probe compound for hydroxyl radicals. Iopromide is also a refractory compound which cannot be effectively degraded in advanced oxidation process like $\mathrm{O}_{3} / \mathrm{H}_{2} \mathrm{O}_{2}$, but can be degraded with sulfate radical oxidation. ${ }^{21,35}$ The two compounds were nearly not degraded in the PDS/CuO oxidation. In contrast, TCE, phenol and chlorophenols were effectively degraded. The result indicates that the surface activated PDS has a lower oxidation potential than hydroxyl radical and sulfate radical. It can be classified as a moderately strong oxidant with certain selectivity for organic pollutants. Since not only phenol and chlorophenols but also TCE were effectively degraded, the PDS/CuO oxidation is not selective only to phenolic compounds. The efficiency of this process on various organic pollutants should be tested in future studies to have a better knowledge on its selectivity and oxidation potential. For 
contaminated groundwater, the competition of low concentrations of dissolved organic matter could reduce the degradation efficiency for the target pollutants, which also should be evaluated for the design of the PDS/CuO oxidation process.

To sum up, results of this study showed that PDS activation without generation of sulfate radicals can be achieved with the $\mathrm{PDS} / \mathrm{CuO}$ coupled process. Its cost in oxidant would be over 10 times lower than sulfate radical oxidation. Its efficacy for various other pollutants should be further tested to get more detailed knowledge on its selectivity. Since the PDS/CuO process demonstrated a good dechlorination capacity for $2,4-\mathrm{DCP}$, it would be interesting to study whether it is also good for other halogenated pollutants. Copper leaching could be a problem when the PDS/CuO is applied at acidic $\mathrm{pH}$ and high PDS dosage. It was reported that metal leaching can be significantly reduced with appropriate support materials or fabrication of ferrite spinel structures. ${ }^{36,37}$ These protocols should be tested to anchor $\mathrm{CuO}$ for PDS activation in future studies.

\section{ASSOCIATED CONTENT}

Supporting Information. Procedures of ATR-FTIR and Raman characterization, one table and 11 figures. This material is available free of charge via the Internet at http://pubs.acs.org.

\section{ACKNOWLEDGEMENTS}

The authors want to thank Dr. Haibo Zhu of KAUST Catalysis Center for BET analysis and Ms. Tong Zhan of WDRC for ICP-MS analysis. We also want to thank the anonymous reviewers for their valuable revision suggestions which significantly improved this manuscript.

\section{REFERENCES}


1. Anipsitakis, G. P.; Dionysiou, D. D., Radical generation by the interaction of transition metals with common oxidants. Environ. Sci. Technol. 2004, 38, (13), 3705-3712.

2. Johnson, R. L.; Tratnyek, P. G.; Johnson, R. O., Persulfate Persistence under Thermal Activation Conditions. Environ. Sci. Technol. 2008, 42, (24), 9350-9356.

3. Furman, O. S.; Teel, A. L.; Watts, R. J., Mechanism of Base Activation of Persulfate. Environ. Sci. Technol. 2010, 44, (16), 6423-6428.

4. Guan, Y. H.; Ma, J.; Li, X. C.; Fang, J. Y.; Chen, L. W., Influence of pH on the Formation of Sulfate and Hydroxyl Radicals in the UV/Peroxymonosulfate System. Environ. Sci. Technol. 2011, 45, (21), 9308-9314.

5. Drzewicz, P.; Perez-Estrada, L.; Alpatova, A.; Martin, J. W.; Gamal El-Din, M., Impact of Peroxydisulfate in the Presence of Zero Valent Iron on the Oxidation of Cyclohexanoic Acid and Naphthenic Acids from Oil Sands Process-Affected Water. Environ. Sci. Technol. 2012, 46, (16), 8984-8991.

6. Anipsitakis, G. P.; Dionysiou, D. D., Degradation of organic contaminants in water with sulfate radicals generated by the conjunction of peroxymonosulfate with cobalt. Environ. Sci. Technol. 2003, 37, (20), 4790-4797.

7. Lau, T. K.; Chu, W.; Graham, N. J., The aqueous degradation of butylated hydroxyanisole by UV/S2O82-: Study of reaction mechanisms via dimerization and mineralization. Environ. Sci. Technol. 2007, 41, (2), 613-619.

8. Saien, J.; Ojaghloo, Z.; Soleymani, A.; Rasoulifard, M., Homogeneous and heterogeneous AOPs for rapid degradation of Triton X-100 in aqueous media via UV light, nano titania hydrogen peroxide and potassium persulfate. Chemical Engineering Journal 2011, 167, (1), 172-182.

9. Tsitonaki, A.; Petri, B.; Crimi, M.; Mosbæk, H.; Siegrist, R. L.; Bjerg, P. L., In situ chemical oxidation of contaminated soil and groundwater using persulfate: a review. Critical Reviews in Environmental Science and Technology 2010, 40, (1), 55-91.

10. Deng, Y.; Ezyske, C. M., Sulfate radical-advanced oxidation process (SR-AOP) for simultaneous removal of refractory organic contaminants and ammonia in landfill leachate. Water Research 2011, 45, (18), 6189-6194.

11. Li, S.-X.; Wei, D.; Mak, N.-K.; Cai, Z.; Xu, X.-R.; Li, H.-B.; Jiang, Y., Degradation of diphenylamine by persulfate: Performance optimization, kinetics and mechanism. Journal of Hazardous Materials 2009, 164, (1), 26-31.

12. Lau, T. K.; Chu, W.; Graham, N. J. D., The aqueous degradation of butylated hydroxyanisole by UV/S2O82-: Study of reaction mechanisms via dimerization and mineralization. Environ. Sci. Technol. 2007, 41, (2), 613-619.

13. Waldemer, R. H.; Tratnyek, P. G.; Johnson, R. L.; Nurmi, J. T., Oxidation of chlorinated ethenes by heat-activated persulfate: Kinetics and products. Environ. Sci. Technol. 2007, 41, (3), 1010-1015.

14. Liang, C. J.; Guo, Y. Y., Mass Transfer and Chemical Oxidation of Naphthalene Particles with Zerovalent Iron Activated Persulfate. Environ. Sci. Technol. 2010, 44, (21), 8203-8208.

15. Zou, J.; Ma, J.; Chen, L. W.; Li, X. C.; Guan, Y. H.; Xie, P. C.; Pan, C., Rapid Acceleration of Ferrous Iron/Peroxymonosulfate Oxidation of Organic Pollutants by Promoting $\mathrm{Fe}(\mathrm{III}) / \mathrm{Fe}(\mathrm{II}) \mathrm{Cycle}$ with Hydroxylamine. Environ. Sci. Technol. 2013, 47, (20), 11685-11691.

16. Ahmad, M.; Teel, A. L.; Watts, R. J., Mechanism of Persulfate Activation by Phenols. Environ. Sci. Technol. 2013, 47, (11), 5864-5871. 
17. Fang, G. D.; Gao, J.; Dionysiou, D. D.; Liu, C.; Zhou, D. M., Activation of Persulfate by Quinones: Free Radical Reactions and Implication for the Degradation of PCBs. Environ. Sci. Technol. 2013, 47, (9), 4605-4611.

18. Ahmad, M.; Teel, A. L.; Watts, R. J., Persulfate activation by subsurface minerals. Journal of Contaminant Hydrology 2010, 115, (1-4), 34-45.

19. Teel, A. L.; Ahmad, M.; Watts, R. J., Persulfate activation by naturally occurring trace minerals. Journal of Hazardous Materials 2011, 196, (0), 153-159.

20. Hori, H.; Yamamoto, A.; Hayakawa, E.; Taniyasu, S.; Yamashita, N.; Kutsuna, S., Efficient decomposition of environmentally persistent perfluorocarboxylic acids by use of persulfate as a photochemical oxidant. Environ. Sci. Technol. 2005, 39, (7), 2383-2388.

21. Zhang, T.; Zhu, H. B.; Croue, J. P., Production of Sulfate Radical from Peroxymonosulfate Induced by a Magnetically Separable CuFe2O4 Spinel in Water: Efficiency, Stability, and Mechanism. Environ. Sci. Technol. 2013, 47, (6), 2784-2791.

22. Anipsitakis, G. P.; Dionysiou, D. D.; Gonzalez, M. A., Cobalt-mediated activation of peroxymonosulfate and sulfate radical attack on phenolic compounds. Implications of chloride ions. Environ. Sci. Technol. 2006, 40, (3), 1000-1007.

23. Fang, J. Y.; Shang, C., Bromate Formation from Bromide Oxidation by the UV/Persulfate Process. Environ. Sci. Technol. 2012, 46, (16), 8976-8983.

24. Liu, C.; Shih, K.; Sun, C.; Wang, F., Oxidative degradation of propachlor by ferrous and copper ion activated persulfate. Science of the Total Environment 2012, 416, 507-512.

25. Kimura, M., Catalyzed reaction between oxalate ion and peroxodisulfate. I. Copper (II) as catalyst. The Journal of Physical Chemistry 1973, 77, (10), 1265-1270.

26. Barták, P.; Čáp, L., Determination of phenols by solid-phase microextraction. Journal of Chromatography A 1997, 767, (1), 171-175.

27. Gu, B.; Schmitt, J.; Chen, Z.; Liang, L.; McCarthy, J. F., Adsorption and desorption of different organic matter fractions on iron oxide. Geochim. Cosmochim. Acta 1995, 59(2), 219-229.

28. Yang, Y.; Pignatello, J. J.; Ma, J.; Mitch, W. A. Comparison of halide impacts on the efficiency of contaminant degradation by sulfate and hydroxyl radical-based advanced oxidation processes (AOPs). Environ. Sci. Technol. 2014, 48(4), 2344-2351.

29. Zhang, T.; Li, W.; Croué, J.-P., Catalytic ozonation of oxalate with a cerium supported palladium oxide: an efficient degradation not relying on hydroxyl radical oxidation. Environ. Sci. Technol. 2011, 45, (21), 9339-9346.

30. Stumm, W., Chemistry of the solid-water interface: Processes at the mineral-water and particle-water interface in natural systems. John Wiley \& Son Inc.: 1992.

31. Zafiriou, O. C.; Voelker, B. M.; Sedlak, D. L., Chemistry of the superoxide radical (O2-) in seawater: Reactions with inorganic copper complexes. The Journal of Physical Chemistry A 1998, 102, (28), 5693-5700.

32. Hayes, K. F.; Roe, A. L.; Brown, G. E., Jr.; Hodgson, K. O.; Leckie, J. O.; Parks, G. A. In situ $\mathrm{X}$-ray absorption study of surface complexes: Selenium oxyanions on $\alpha$-FeOOH. Science 1987, 238 (4828), 783-786.

33. Farquhar, M. L.; Charnock, J. M.; Livens, F. R.; Vaughan, D. J. Mechanisms of arsenic uptake from aqueous solution by interaction with goethite, lepidocrocite, mackinawite, and pyrite: An X-ray absorption spectroscopy study. Environ. Sci. Technol. 2002, 36 (8), 1757-1762.

34. Li, C.; Hoffman, M. Z. One-electron redox potentials of phenols in aqueous solution. J. Phys. Chem. B 1999, 103(32), 6653-6656 
35. Westerhoff, P.; Yoon, Y.; Snyder, S.; Wert, E., Fate of endocrine-disruptor, pharmaceutical, and personal care product chemicals during simulated drinking water treatment processes. Environ. Sci. Technol. 2005, 39, (17), 6649-6663.

36. Querol, X.; Alastuey, A.; Moreno, N.; Alvarez-Ayuso, E.; García-Sánchez, A.; Cama, J.; Ayora, C.; Simón, M., Immobilization of heavy metals in polluted soils by the addition of zeolitic material synthesized from coal fly ash. Chemosphere 2006, 62, (2), 171-180.

37. Shih, K.; White, T.; Leckie, J. O., Nickel stabilization efficiency of aluminate and ferrite spinels and their leaching behavior. Environ. Sci. Technol. 2006, 40, (17), 5520-5526. 